\title{
NOTAS ADICIONAIS SOBRE A TAXONOMIA E A DISTRIBUIÇÃO GEOGRÁFICA DOS GÊNEROS ALCHORNEOPSIS MUELL. ARG., CLEIDION BLUME E POLYANDRA LEAL (EUPHORBIACEAE- ACALYPHOIDEAE) ${ }^{1}$
}

\author{
Ricardo de S. Secco ${ }^{2}$
}

Recebido em 4/11/1999. Aceito em 30/10/2000

\begin{abstract}
RESUMO - (Notas adicionais sobre a taxonomia e a distribuição geográfica dos gêneros Alchorneopsis Muell. Arg., Cleidion Blume e Polyandra Leal (Euphorbiaceae - Acalyphoideae). Este trabalho apresenta dados taxonômicos e de distribuição geográfica sobre os gêneros Alchorneopsis, Cleidion e Polyandra. Alchorneopsis é um gênero monotípico da América Central, Colômbia, Guianas, Peru e Brasil. Cleidion, com a maioria de suas espécies distribuídas na região paleotropical, apresenta apenas três espécies na América Tropical. Polyandra, um gênero monotípico, é provavelmente endêmico da Amazônia brasileira. As relações taxonômicas dos gêneros estudados são discutidas e as espécies amazônicas ilustradas e comentadas.
\end{abstract}

Palavras-chave - Taxonomia, Euphorbiaceae, Alchorneopsis, Cleidion, Polyandra, Amazônia

\begin{abstract}
Additional notes on taxonomy and geographic distribution of the genera Alchorneopsis Muell. Arg., Cleidion Blume and Polyandra Leal (Euphorbiaceae - Acalyphoideae). Complementary data are presented and discussed with regard to the taxonomy and geographic distribution of the genera Alchorneopsis, Cleidion and Polyandra. Alchorneopsis is a probably monotypic genus from Central América, Colômbia, Guiana, Peru and Brazil. Cleidion, with the majority of their 25 species in the paleotropics, has only three species in Tropical America. Polyandra, a monotypic genus, is probably endemic from Brazilian Amazonia. The taxonomic relations of the genera and species are discussed and the Amazonian species are illustrated.
\end{abstract}

Key words - Taxonomy, Euphorbiaceae, Alchorneopsis, Cleidion, Polyandra, Amazonia

\section{Introdução}

A família Euphorbiaceae vem sendo estudada por um grupo multidisciplinar, que desenvolve pesquisas avançadas em palinologia, fitoquímica e filogenia, mas ainda apresenta sérios problemas taxonômicos que dificultam a compreensão de muitos gêneros. Este é o caso de Alchorneopsis Muell. Arg., Cleidion Blume e Polyandra Leal, cuja taxonomia ainda é obscura e confusa.

Alchorneopsis é um gênero neotropical, de ocorrência registrada para a América Central e América do Sul, cuja delimitação de suas espécies levou Webster (1994) a considerá-las como provavelmente conspecíficas.

\footnotetext{
Bolsa de Pesquisa (CNPq)

2 Departamento deBotânica, CNPq-Museu Paraense Emilio Goeldi, C. Postal 399, CEP 66040-170, Belém, PA, Brasil
} 
Cleidion é um gênero com cerca de 25 espécies (Webster 1994), sendo a maioria delas da região paleotropical, com três espécies neotropicais distribuídas pelo México, América Central e América do Sul. Dessas, duas foram descritas para o Brasil (Amazônia e Nordeste), sendo entretanto pouco conhecidas e mal representadas nos herbários.

Polyandra é um gênero monotípico, conhecido até agora apenas de sua coleção-tipo proveniente da Amazônia brasileira, cuja identidade e posição sistemática são ainda motivo de controvérsias.

Nenhum desses gêneros foi criticamente estudado, sendo os registros mais recentes sobre os mesmos os de Gillespie (1993) e Webster (1994). Tanto as coleções de Alchorneopsis como de Cleidion têm sido erroneamente identificadas como pertencentes ao gênero Alchornea Sw., especialmente quando apresentam-se estéreis ou apenas com flores pistiladas e/ou frutos. No presente trabalho são apresentadas e discutidas algumas informações esparsas contidas na literatura, bem como novidades sobre Cleidion, Alchorneopsise Polyandra, visando fornecer subsídios para atualizar a taxonomia e a fitogeografia desses táxons, enfatizando-se as espécies representadas na Amazônia brasileira, por serem as menos conhecidas desses gêneros.

\section{Resultados e discussão}

I. Alchorneopsis Muell. Arg., Linnaea 34: 156. 1865

Gênero cujo número exato de espécies tem sido objeto de controvérsia, sendo que os autores mais recentes (Jablonski 1967; Gillespie 1993) aceitam apenas uma, Alchorneopsis floribunda (Benth.) Muell. Arg., com distribuição geográfica restrita à América Central e região amazônica.

1. Alchorneopsis floribunda (Benth.) Muell. Arg., Linnaea 34:156. 1865. Tipo. BRASIL, Amazonas, Spruce 2681 (holótipo, K; isótipo, NY!).
Fig. 1 - 4.

Alchornea glandulosa var. ? floribunda Benth., Hooker's J. Bot. Kew Gard. Misc. 6: 331. 1854.

Alchorneopsis trimera Lanj., Euphorb. of Surinam, 1931. Tipo. SURINAME, Sectie O, Arbor n. 517, 1.III.1917, fl, fr, Herb. 2696 (holótipo, U; isótipo IAN!)

Árvores dióicas 6-28m alt., 22-35cm DAP; ritidoma estriado, lenticelado. Ramos glabros. Folhas simples, alternas, com nervação actinódroma suprabasal, 3-nervadas, pecíolo 2-3cm compr., canaliculado, glabro; limbo 6,516 x 4-6,5cm, elíptico, subcoriáceo a coriáceo, ápice acuminado, base levemente cuneada com um par de glândulas, mais evidentes na face abaxial; faces abaxiais com nervuras proeminentes, evidenciando a principal, duas secundárias a partir da base, 1 a 2 acima da parte mediana da lâmina; face adaxial com nervuras planas e levemente proeminentes, com rede de nervuras terciárias mais evidentes que na face abaxial. Inflorescências estaminadas isoladas ou geminadas em racemos espiciformes axilares ou às vezes terminais, $6-12 \mathrm{~cm}$ compr., a raque tomentosa; flores estaminadas monoclamídeas, aos pares ou em tríades ou glomérulos de poucas flores, com pedicelos $1 \mathrm{~mm}$ compr., densopubescentes, cálice com lobos 3-4, elípticos, 1$1,5 \mathrm{~mm}$ compr., pubescentes, tricomas simples; estames 2,5mm compr., rodeados por um disco pubescente, anteras ovais, pistilódio trímero, glabro, disposto no centro do androceu. Inflorescências pistiladas isoladas ou geminadas, em racemos espiciformes, axilares, ca. $6-10 \mathrm{~cm}$ compr., a raque tomentosa; flores pistiladas isoladas na raque, com 3 bractéolas na base, pedicelos $1 \mathrm{~mm}$ compr., denso-pubescentes; sépalas (3)4, livres, ovais, 0,5-1mm compr., pubescentes, tricomas simples; ovário 3-locular, piriforme, $1,5 \mathrm{~mm}$ compr., tomentoso, rodeado por disco piloso, estiletes 3, curtos, glabros. Frutos (depauperados nas amostras analisadas) com 


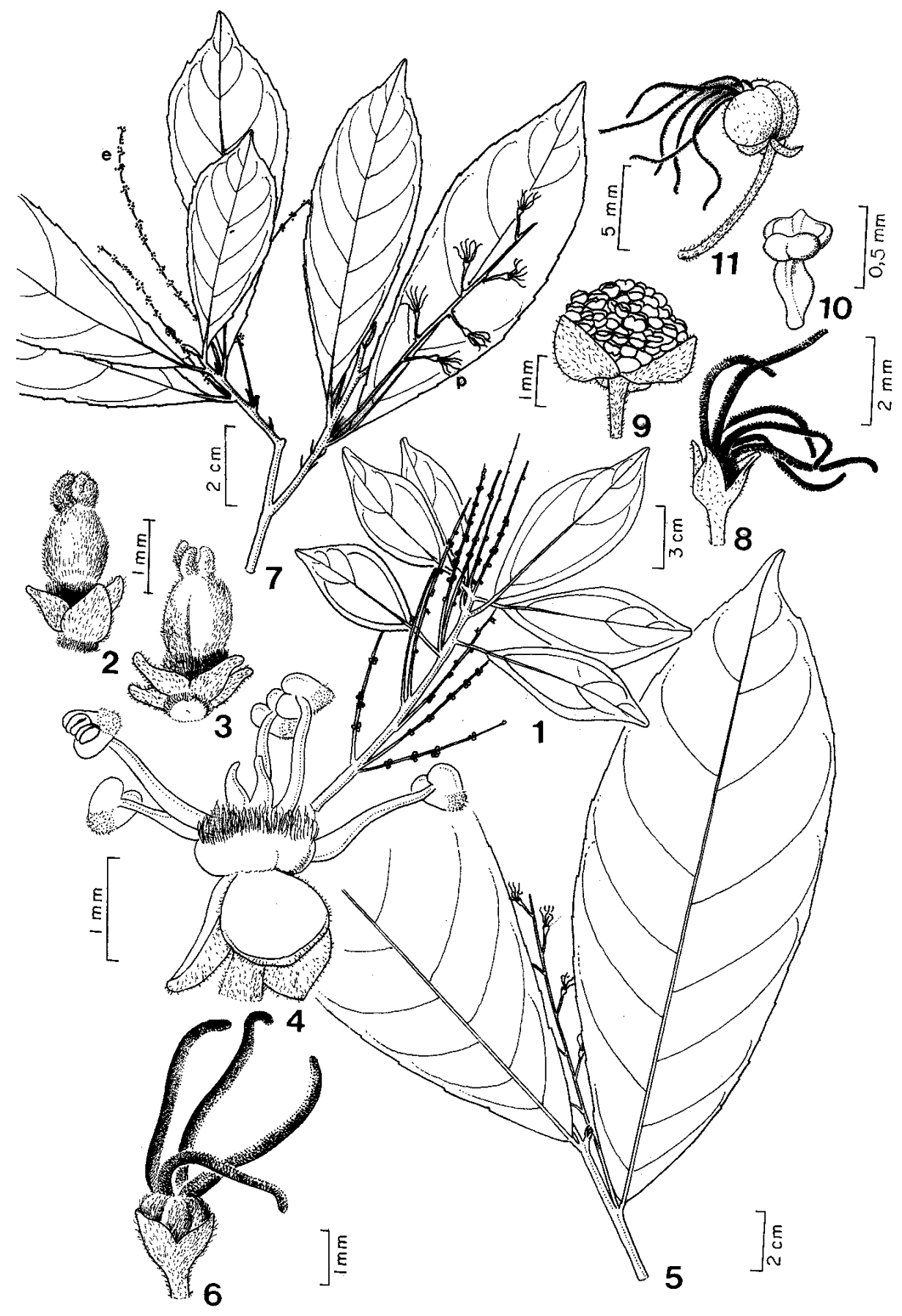

Figuras 1-4. Alchorneopsis floribunda (Benth.) Muell. Arg. 1. Ramo com inflorescência em racemo (Krukoff 6386); 23. Flores pistiladas com cálice trímero (Herb. 2696) e pentâmero (N. A. Rosa 733), respectivamente; 4. Flor estaminada com pistilódio central (Krukoff 6386). Figuras 5-6. Cleidion amazonicum Ducke. 5. Ramo com inflorescência pistilada em racemo; 6. Flor pistilada com ovário bilocular (Ule 5262). Figuras 7-11. Cleidion tricoccum (Casaretto) Baillon. 7. Ramo com inflorescências estaminadas (e) e pistiladas (p); 8. Flor pistilada com ovário trilocular; 9. Flor estaminada; 10. Estame; 11. Fruto jovem (J. C. Moraes 1084). 
3 mericarpos comprimidos, pubescentes, sementes muricadas, $2,5 \mathrm{~mm}$ compr.

Distribuição: (Fig.17). Alchorneopsis floribunda apresenta ampla distribuição geográfica, ocorrendo desde a América Central (Costa Rica e Panamá) até a América do Sul, nas Guianas, Peru e Brasil. No território brasileiro ocorre exclusivamente na Amazônia, nos Estados de Roraima, Amapá, Amazonas, Acre e Pará, nas matas de terra firme, de várzea e caatingas.

A presença de Alchorneopsis, tanto na América Central como do Sul, talvez seja um bom exemplo para a idéia da migração de plantas da América do Sul em direção ao norte, há cerca de três milhões de anos atrás, estabelecendo-se nas florestas da América Central, defendida por Gentry (1982). Segundo o mesmo autor, devido a separação das Américas ter sido muito recente, a diferenciação morfológica entre as espécies atuais seria ainda muito pequena. Isto parece estar bem de acordo com o gênero Alchorneopsis, cuja ocorrência na América Central motivou a descrição de uma outra espécie, Alchorneopsis portoricensis Urb., com características morfológicas muito semelhantes às de $A$. floribunda.

Material examinado: BRASIL. Amapá: rio Oiapoque, IX/60 (fl.), H. S. Irwin et al. 48364 (IAN, MG, NY). Pará: Belém, igapó do Catu, X/66 (fr.), Pires \& N. T. Silva 10.263(IAN); rio Jari, serra de Monte Dourado, XI/67 (fl.), $E$. Oliveira 3553 (IAN). Roraima: Axinim, along rio Abacaxis VII/83 (fl.), Zarucchi et al. 2991 (INPA, MG). Amazonas: estrada Manaus Itacoatiara, reserva Ducke, XII/95 (fl.), J. R. Nascimento 687(INPA); mesmo local, V/95 (fl.), Cordeiro 1538(INPA); Barcelos, rio Solimões, IX/68 (fl.), M. Silva 1968(MG); Humaitá, Três Casas, IX/34 (fl.), B. A. Krukoff 6386(IAN); rio Negro, Jauaperi, II/77 (fl.), M. R. Santos 105 (INPA, MG, NY). Acre: Cruzeiro do Sul, Projeto RADAM, II/76 (fl.), N. A. Rosa 733(IAN); sub-base Cruzeiro do Sul, II/76 (fl.), L. R. Marinho 141 (IAN).

Com base em Alchornea glandulosa var. floribunda Benth., Mueller (1865) estabeleceu o gênero Alchorneopsis com uma única espécie, Alchorneopsis floribunda. A segunda espécie descrita para o gênero, Alchorneopsis portoricensis (Urban 1899), assim como a primeira, foi também descrita apenas com base nas flores estaminadas.

Posteriormente, Lanjouw (1931) descreveu uma terceira espécie, $A$. trimera, para a Guiana, sem analisar as flores estaminadas do táxon. Referida espécie apresenta o cálice da flor pistilada com 3 sépalas. Segundo Lanjouw (1931), $A$. trimera seria muito semelhante à $A$. portoricensis, e que provavelmente as duas poderiam tratar-se de uma mesma espécie. Jablonski (1967) também colocou em dúvida a identidade de A. portoricensis. Autores como Jablonski (1967) e Gillespie (1993) consideraram $A$. trimera como sinônimo de $A$. floribunda, sem, entretanto, apresentarem uma justificativa crítica para tal posicionamento.

Webster (1994), em sua moderna classificação das Euphorbiaceae, comenta que Alchorneopsis apresenta 3 espécies descritas, mas que provavelmente devam ser conspecíficas.

A análise de um isótipo de $A$. trimera Lanj., depositado no herbário IAN, revelou que o cálice das flores estaminadas ou pistiladas pode ser trímero ou tetrâmero, que também podem ser encontrados em $A$. floribunda, segundo a descrição original. Portanto, o número de peças do cálice, caráter usado para separar espécies desse gênero, tem pouco valor taxonômico. Diante do exposto, concordou-se com Jablonski (1967) e Gillespie (1993) quanto à sinonimização de $A$. trimera à $A$. floribunda.

Segundo Nowicke et al. (1999), os grãos de pólen de Alchorneopsis floribunda apresentam a ornamentação da exina do tipo levemente estriado-reticulada, que seria uma ocorrência rara em Acalyphoideae, enquanto que em $A$. portoricensis a ornamentação é do tipo irregularmente punctada. Devido a essa diferença, acredita-se que provavelmente $A$. portoricensis 
seja uma espécie distinta de $A$. floribunda. Entretanto, aguarda-se amostras com flores pistiladas para melhor discutir a identidade dos referidos táxons.

Apesar de ser freqüentemente confudido com Alchornea nos herbários amazônicos, Alchorneopsis se diferencia facilmente por apresentar tricomas simples (em Alchornea são estrelados); presença de pistilódio na flor estaminada; estames em número de 5-6, com filetes mais longos (em Alchornea frequientemente são 8, com filetes curtos) e os estiletes curtos, em número de 3 , enquanto que em Alchornea os estiletes são longos, em número de 2 (raro 3 ).

Alchorneopsis floribunda é uma árvore de grande porte, com raízes tabulares e ritidoma fissurado, sendo facilmente identificada por apresentar as folhas trinervadas, inflorescências delicadas em racemos espiciformes, os estames rodeados por um disco de tricomas, ovário piriforme, com 3 estiletes curtos e flores estaminadas com pistilódio trímero no centro do androceu.

II. Cleidion Blume, Bijdr. Fl. Ned. Ind. 612. 1826. Redia Casaretto, Nov. Stirp. Bras. 51. 1843 Psilostachys Turcz., Bull. Soc. Imp. Naturalistes Moscou 16: 58. 1843

Lasiostyles Presl., Abh. Königl. Böhm. Ges. Wiss. v. 3: 579. 1845

Tetraglossa Beddome, Madras J. List. Sci. II. 22: 70.1861

Arbustos, arvoretas a árvores, dióicos, raro monóicos, indumento de tricomas simples. Ramos glabros, esparsamente lenticelados. Folhas com pecíolos pubescentes; limbo cartáceo ou membranáceo, ápice acuminado, base arredondada, tricomas simples na face abaxial, pubescente, principalmente sobre as nervuras; margens denteadas, glândulas globosas no limbo. Inflorescência estaminada em racemo axilar ou terminal, flores dispostas em glomérulos. Flores estaminadas monoclamídeas, curto-pediceladas, cálice com 3-4 lobos, estames 35-80, conectivo conspicuamente desenvolvido; anteras apiculadas, 4 locelos. Inflorescência pistilada em racemo axilar. Flores pistiladas longo-pediceladas, monoclamídeas ou raramente com pétalas rudimentares, cálice 3-lobado, raramente 4-5 lobado, ovário 2-3 locular, densamente piloso, lóculos 1-ovulados, estiletes 2-3, profundamente 2-fidos. Fruto cápsula com 2-3 mericarpos, sementes sem carúnculas.

Cleidion diferencia-se de Alchornea por apresentar tricomas simples, estames 50-80, com as anteras 4-loceladas e o ovário com estiletes densamente papilosos, enquanto Alchornea apresenta tricomas estrelados, estames 8 , anteras biloculares e ovário com estiletes papilosos a lisos.

Cleidion é um gênero pantropical, cuja maioria das espécies distribui-se na Ásia e África, sendo apenas três encontradas na região neotropical (Fig. 17), desde o México, América Central (Honduras, Guatemala e Panamá) e América do Sul (Colômbia, Venezuela, Peru, Brasil e Bolívia). É, portanto, um gênero disjunto entre o Velho e o Novo Mundo, sendo que essa distribuição fornece evidências da ligação florística que teria existido entre as áreas tropicais da África e América do Sul, conforme tem sido discutido por autores como Thorne (1973) e Smith (1973).

A presença de Cleidion na Ásia parece confirmar o que diz Smith (1973), para quem evidências da história evolucionária indicam que provavelmente a África e a América do Sul receberam seus estoques iniciais de Angiospermas de diferentes direções, incluindo o sudeste da Ásia e a Malásia.

Cleidion também é disjunto entre a Amazônia e o Nordeste do Brasil (Pernambuco e Bahia), o que parece reforçar a hipótese de Andrade-Lima (1966) sobre uma possível ligação que teria havido, no período Quaternário, entre a floresta amazônica e a mata atlântica do Nordeste.

Apesar das espécies de Cleidion serem pouco conhecidas e mal coletadas, provavelmente devido a raridade de sua ocorrência, apresen- 
tam boa representatividade na América do Sul.

Chave para as espécies de Cleidion que ocorrem na Amazônia brasileira

1. Folhas ovais a oval-lanceoladas; ovário 3locular, estiletes 3 , fruto 3-carpelar C. tricoccum

1. Folhas elípticas, elíptico-oblongas; ovário 2locular, estiletes 2, fruto 2-carpelar C. amazonicum

1. Cleidion amazonicum Ule, Verhandl. Bot. Ver. Bradenburg 50: 76. 1908. Tipo. BRASIL. Pará: rio Juruá, Marary, IX/1900, fl. pistilada, Ule 5262 (holótipo, MG!; isótipo, B).

Fig. 5-6.

Arbusto ou arvoreta 2-6m alt., às vezes escandente. Folhas com pecíolo 0,3-1 cm compr., levemente canaliculado; limbo cartáceo, 9-23,5x $3,5-8,5 \mathrm{~cm}$, elíptico a elíptico-oblongo, face adaxial com nervuras planas a levemente impressas, glabra; face abaxial com nervuras proeminentes, pubescente nas nervuras, especialmente na principal. Inflorescência estaminada $5-8 \mathrm{~cm}$ compr., raque pubescente, tricomas simples; flores estaminadas analisadas em fase jovem (a maioria em botões), botões com ápice pubescente, pedicelo $1-1,5 \mathrm{~mm}$ compr., pubescentes, estames numerosos. Inflorescência pistilada 6-19,5cm compr., raque pubescente, flores isoladas, às vezes aos pares ou em tríades; flores pistiladas com pedicelos $0,6-1,5 \mathrm{~cm}$ compr., pubescentes, bractéolas 3, na base; cálice com 3 (4-5) lobos lanceolados, 1,5-2 x 0,5mm, pubescentes externamente, especialmente nas margens, glabros internamente; ovário hirsuto, tricomas simples, 2-locular, 1-2mm diâm., estiletes 2, 4,5-8mm compr., face ventral densopapilosa, face dorsal pubescente. Fruto jovem ca. $6 \mathrm{~mm}$ diâm., 2-carpelar, pubescente, estiletes persistentes.

Distribuição (Fig. 17). Espécie típica das matas de várzea, de ocorrência aparentemente rara nos Estados do Amazonas, Acre, Pará e Mato Grosso, Cleidion amazonicum estende-se também ao Peru e à Bolívia.

Material examinado. BRASIL. Pará: basin of rio Xingu, Gleba Bacaja, rio Bacaja, Genipapo trail, XI/80 (fl. estaminada), Prance et al. 26512 (INPA, MG, NY); mesmo local, XI/80 (fl. pistilada), Prance et al. 26511 (INPA, MG, NY); rio Tapajós, Vila Braga, I/18 (fl. estaminada), Ducke MG 16903 (MG); Baixo Rio Xingu, município Senador José Porfírio, ilha Mucuripe, X/ 85 (fl. pistilada), S. S. Almeida 364 (MG); near EMBRAPA Station, at Km 23 on the road Altamira - Itaituba, X/77 (fl. pistilada), $C$. $C$. Berg et al. 741 (INPA, MG, NY); rio Tapajós, igarapé das Furnas, XII/17 (fl. pistilada), Ducke $M G 16860$ (MG). Amazonas: margem do rio Trombeta, Porteira, base do proj. RADAM XII/73 (fl.), B. S. Pena 401 (IAN). Mato Grosso: rio São Manoel, II/52 (fl.), J. M. Pires 3747 (IAN). PERU. Ucayali: Cel. Portillo, IV/88 (fl.), Vazquez \& Jaramillo 10515 (MO). BOLÍVIA. Beni, XI/85 (fr.), Solomon 14595 (MO).

Esta é a única espécie de Cleidion da região neotropical que apresenta o ovário 2-locular, caráter incomum no gênero. Geralmente exibe folhas maiores que as de $C$. tricoccum, variando entre $9-23 \mathrm{~cm}$ de comprimento, por $4-9 \mathrm{~cm}$ de largura.

Apesar de ser razoavelmente conhecida na Amazônia, essa espécie precisa ser melhor coletada, uma vez que as amostras com flores estaminadas são raríssimas nos herbários e quando existem são parte de inflorescências jovens ou depauperadas, difíceis de serem analisadas.

2. Cleidion tricoccum (Casaretto) Baillon, Rec. d'obs. Bot. IV. 370. 1863. Tipo. BRASIL. Bahia: St. Amaro, Casaretto (lectótipo, G); Rio de Janeiro, A. St. Hillaire 562 (sintipo, P!); Bahia, Salzmann (síntipos, MPU, BR, K, P)

Fig. 7-11.

Redia tricocca Casaretto, Stirp. Nov. Bras. Decad. VI. 51. 1843. 
Arbusto, arvoreta ou árvore 2-8m alt. Folhas com pecíolo 0,3-0,5(1)cm compr., levemente canaliculado, pubescente, glabrescente; limbo cartáceo, 6,5-15(18,5) x 3-6,5cm, oval a ovallanceolado, face adaxial com nervuras planas, glabra; face abaxial com nervuras proeminentes, pubescente nas nervuras, tricomas simples. Inflorescência estaminada 5-6cm compr., raque pubescente; flores estaminadas com 3 sépalas, côncavas, pubescentes externamente, pedicelos 1-1,5mm, pubescentes, estames numerosos (ca. 50), ca. $1 \mathrm{~mm}$ compr., glabros. Inflorescência pistilada $3-9 \mathrm{~cm}$ compr., raque pubescente, flores isoladas ou aos pares, às vezes em tríades; flores pistiladas com pedicelos 5-9mm compr., pubescentes; cálice com 3(4) lobos lanceolados, 1,5-2mm compr., pubescentes externamente, especialmente nas margens, glabros internamente; ovário denso-piloso, tricomas simples, 3locular, 1,5-2mm diâm., estiletes 3, com 5-10mm compr., face ventral denso-papilosa, face dorsal pubescente, tricomas simples. Fruto imaturo 3,5mm diâm., 3-carpelar, pubescente, estiletes persistentes.

Distribuição (Fig. 17). Cleidion tricoccum apresenta uma distribuição restrita no Brasil e Bolívia, sendo aí encontrada em bosque montano alterado, de acordo com Caballero (1993). No Brasil, a espécie é encontrada na mata Atlântica nordestina (Pernambuco e Bahia) e no Sudeste (Rio de Janeiro, Espírito Santo e São Paulo), em beira de rios e matas úmidas. Ocorre também em matas de várzea, nos Estados do Amazonas e Pará.

Material examinado. BRASIL. Amazonas: Km 1-4 road Boca do Acre to Rio Branco, X/66 (fl. pistiladas), Prance et al. 2301 (INPA, MG, NY); rio Purus, between Tapaua e Piranhas, XI/71 (fl., fr.), Prance et al. 16347(INPA, MG, NY). Pará: rio Traíra, lago Cotijuba, rio Xingu, ilha Belo Horizonte, X/86 (fl.), A. T. G. Dias et al. 249 (MG). Pernambuco: Nazaré da Mata, IV/54 (fl.), J. C. Moraes 1084 (IAN). BOLÍVIA. Pando: Prov. Nicolas Suarez, rio Tahuamanú, X/89 (fl.), Beck et al. 19.239(LPB,
MG); Pando: Prov. Manuripi, rio Manuripi, X/ 89 (fl.) Beck et al. 19551 (LPB, MG).

Cleidion tricoccum geralmente apresenta folhas menores $(6,5-15(20) \mathrm{cm}$ compr.) que $C$. amazonicum, mas a principal característica que a distingue daquela espécie é o ovário 3-locular e o fruto padrão tricoca. A amostra analisada no herbário IAN (J. C. Moraes 1084) evidencia um espécime monóico.

3. Cleidion castaneifolium Muell. Arg., Linnaea 34: 184. 1865. Tipo. PERU. Pavon (holótipo, G, n. v; isótipo IAN, foto!)

Cleidion membranaceum Pax \& K. Hoffm., Pflanzenreich 4, 147. XIV: 23. 1919. Tipo. VENEZUELA. Lara: Palmosola, rio Aroa, 26 28/VI/13, fl, fr?, Pittier 6375 (holótipo, US!). Syn. nov.

Alchornea oblongifolia Standley, Carnegie Inst. Wash. Publ. 461: 66. 1935.

Cleidion woodsonianum Croizat, J. Arnold Arbor. 24: 167. 1943. Tipo. Panamá. Salamanca Hydrographic Station, rio Pequeni, s/dat., Woodson et al. 1587 (holótipo, A; isótipos F, MO!, NY).Syn. nov.

Cleidion oblongifolium (Standley) Croizat, J. Arnold Arbor. 24: 166. 1943. Tipo. Guatemala. Petén: Camp 35, boundary with Belize, Schipp S - 279 (holótipo, F; foto F!)

Arbusto ou arvoreta 2-3,5m alt., ou árvore até $10 \mathrm{~m}$ alt. Folhas com pecíolo $1,5-5 \mathrm{~cm}$ compr., pubescentes a glabras; limbo membranáceo a cartáceo, 15-26x6,5-9,5cm, oval, elíptico a elíptico-oboval, face adaxial com nervuras planas, glabra; face abaxial com nervuras levemente proeminentes, pubescente nas nervuras. Inflorescência estaminada 5-9cm compr., raque pubescente; flores estaminadas com sépalas 3, cuculadas, glabras a levemente pubescentes, pedicelos $1 \mathrm{~mm}$ compr., esparso-pubescentes a glabros, estames ca. 60-80, ca. $1 \mathrm{~mm}$ compr., glabros. Inflorescência pistilada $12-16 \mathrm{~cm}$ compr., raque glabra a esparsamente pubescente, flores isoladas, aos pares ou em tríades; flores 
pistiladas com pedicelos $5-9 \mathrm{~mm}$ compr., pubescentes; cálice 3(4-5), às vezes 4-6 lobos (Pax \& Hoffmann 1919), lobos lanceolados, 1$2 \mathrm{~mm}$ compr., pubescentes externamente, ovário hirsuto, 3-locular, 1,5-2mm diâm., estiletes 3$5 \mathrm{~mm}$ compr., face ventral papilosa, dorsal pubescente. Fruto jovem 7-9mm diâm., na fase madura 13-18mm diâm., 3-carpelar, algumas vezes apenas 2 mericarpos desenvolvidos, 1 deles atrofiado, densamente pubescente, estiletes persistentes, 7-12mm compr., profundamente bífidos, pubescentes.

Distribuição (Fig. 17). Cleidion castaneifolium apresenta uma ampla distribuição a partir do México, na região de Chiapas, até a América Central no Panamá, em Honduras e Guatemala, e América do Sul no Equador, Colômbia, Venezuela e Peru.

Nomes vulgares: "cepanchito" (Peru), "palay" (Equador).

Material examinado: PANAMÁ. Darién VII/68 (fl., fr.), Hartman 12038(MO). EQUADOR. Borbón, IX. 65 (fl.), Little \& Dixon 21041 (MO). COLÔMBIA. Município de Turbo, VIII/87 (fl.), Callejas et al. 4986 (MO). VENEZUELA. Estado Yaracuy, Falcon, rio Tocuyo, VIII/70 (fr.), Carlos Blanco C. 895 (MO); Estado Falcon, VI/79 (fr.), Liesneret al. 7722 (MO).

Essa espécie foi referida recentemente por Webster \& Huft (1988) para o Panamá, e por Méroz (1990) para o Peru, sendo que ambos não analisaram a flor pistilada, estudada no presente trabalho. Segundo Mueller (1865), a flor estaminada apresenta cerca de 70 estames e o fruto é uma cápsula 6-lobada, o que provavelmente é um equívoco.

Cleidion castaneifolium distingue-se facilmente de $C$. amazonicum e $C$. tricoccum por apresentar o pecíolo longo (1,5-5cm de comprimento), caráter este pouco comum nas coleções analisadas de Cleidion da Amazônia brasileira, e também por seus frutos maiores $(13-18 \mathrm{~mm}$ de diâmetro).

De acordo com Webster \& Huft (1988), Cleidion membranaceum poderia ser um sinô- nimo de $C$. tricoccum. Analisando-se a diagnose de C. membranaceum, proposta por Pax \& Hoffmann (1919), bem como as coleções acima destacadas, foram verificadas algumas diferenças apontadas por aqueles autores para a espécie, como pecíolo com $2-3 \mathrm{~cm}$ de comprimento e cápsulas com $8 \mathrm{~mm}$ diâm., que podem ser encontradas em C. castaneifolium. Ainda Pax \& Hoffmann (1919) informam que a flor pistilada de C. membranaceum apresenta cálice com 4-6 lobos, sendo 3 maiores, lanceolados, o que também foi encontrado, embora raramente, em $C$. castaneifolium e C. amazonicum. Entretanto, analisando-se alguns exemplares-tipo de $C$. membranaceum verificou-se extrema semelhança com C. castaneifolium. Por este motivo, optou-se por sinonimizar $C$. membranaceum com C. castaneifolium.

\section{Espécie duvidosa}

1. Cleidion prealtum Croizat, J. Arnold Arb. 24: 167. 1943. Tipo. BRASIL. Amazonas: município de Humaitá, Três Casas, fl., Krukoff 6458 (Isótipo, MO!).

Fig. 12-13.

Essa espécie está comentada na discussão sobre o gênero Polyandra, apresentada a seguir neste trabalho.

III. Polyandra Leal, Arq. Jard. Bot. 11: 63. 1951.

Gênero monotípico, coletado até o presente apenas na Amazônia brasileira.

1. Polyandra bracteosa Leal, Arq. Jard. Bot. 11: 63. 1951. Tipo. BRASIL. Amazonas: Borba, rio Madeira, 7/XI/35, fl, Ducke RB 35492 (holótipo, RB!).

Fig. 14-16.

Árvore dióica. Ramos jovens pubescentes, indumento de tricomas estrelados. Folhas com pecíolo canaliculado, rugoso, $2-2,5 \mathrm{~cm}$ compr., 


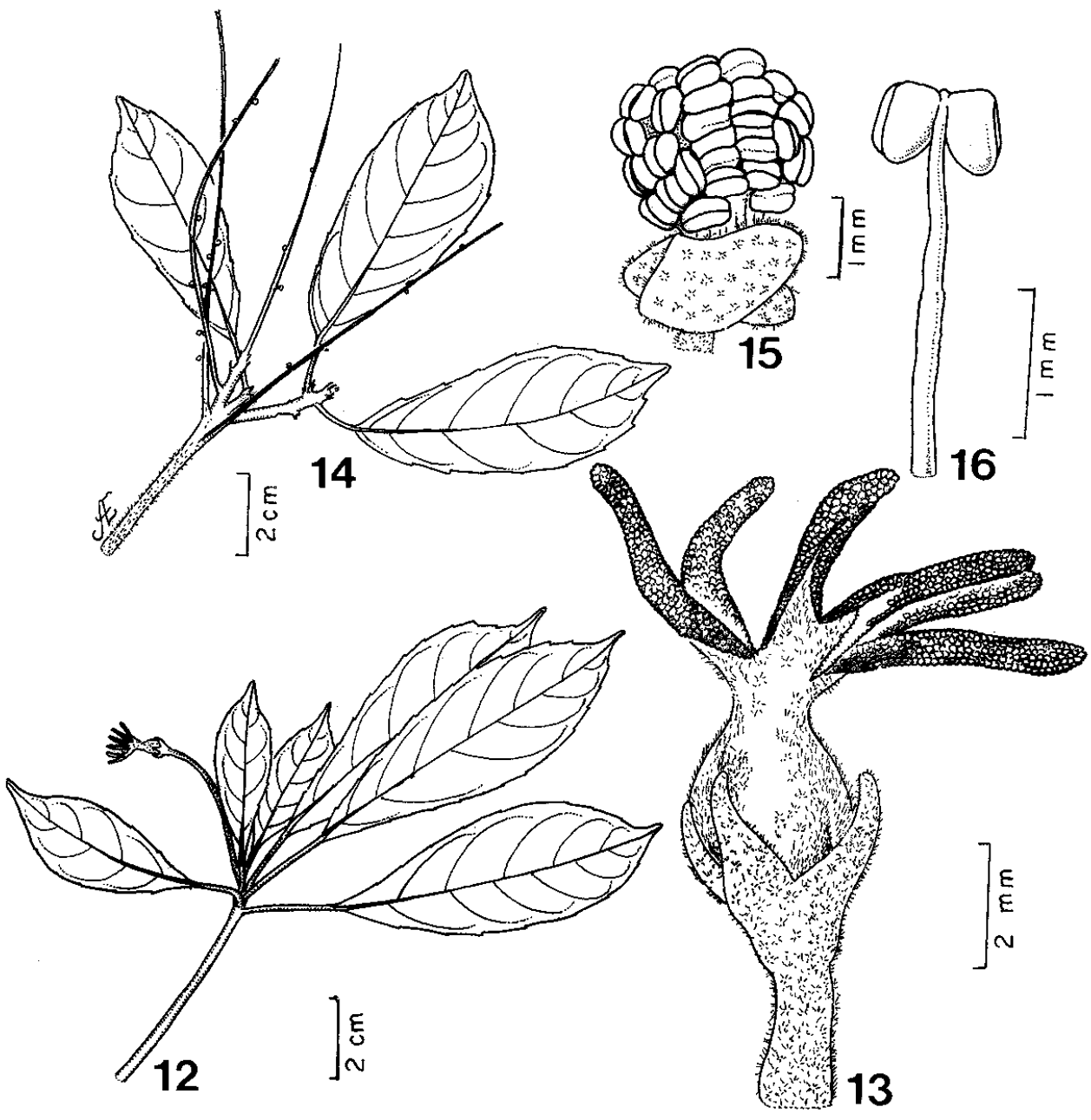

Figuras 12-13. Cleidion prealtum Croizat. 12. Ramo com flor pistilada; 13. Flor pistilada com estilete rugoso concrescido com o ovário (Krukoff 6458). Figuras 14-16. Polyandra bracteosa Leal. 14. Ramo com inflorescência estaminada em racemo; 15. Flor estaminada; 16. Estame (Ducke RB 35492).

pubescente, com pulvino apical; estípulas 2, lanceoladas, 3-3,5mm compr.; limbo 5-8,5cm x 2-2,5cm, elíptico a oboval, cartáceo, face adaxial com nervuras planas, a abaxial com nervuras levemente proeminentes, ambas pubescentes, tricomas concentrados nas nervuras, domácias de tricomas estrelados na junção da nervura principal com as secundárias, ápice acuminado, base obtusa, margem crenada. Inflorescência estaminada em racemo axilar ou terminal,10$12 \mathrm{~cm}$ compr., raque densamente pilosa, tricomas estrelados. Flores estaminadas monoclamídeas, isoladas, raramente aos pares ou em tríades, com 1-2 bractéolas basais, $1 \mathrm{~mm}$ compr., cálice com 3 sépalas, 1,5-2mm compr., valvares, côncavas, ovais, pubescentes externamente, pedicelos 1$1,5 \mathrm{~mm}$ compr., pubescentes, estames ca. 50, 2 $3 \mathrm{~mm}$ compr., livres, glabros, anteras dorsifixas, as tecas elípticas. Inflorescência pistilada e frutos não vistos.

Distribuição (Fig. 17). Polyandra bracteosa parece ser endêmica do Estado do Amazonas, no Brasil, tendo sido coletada apenas nas matas de terra firme do rio Madeira. 


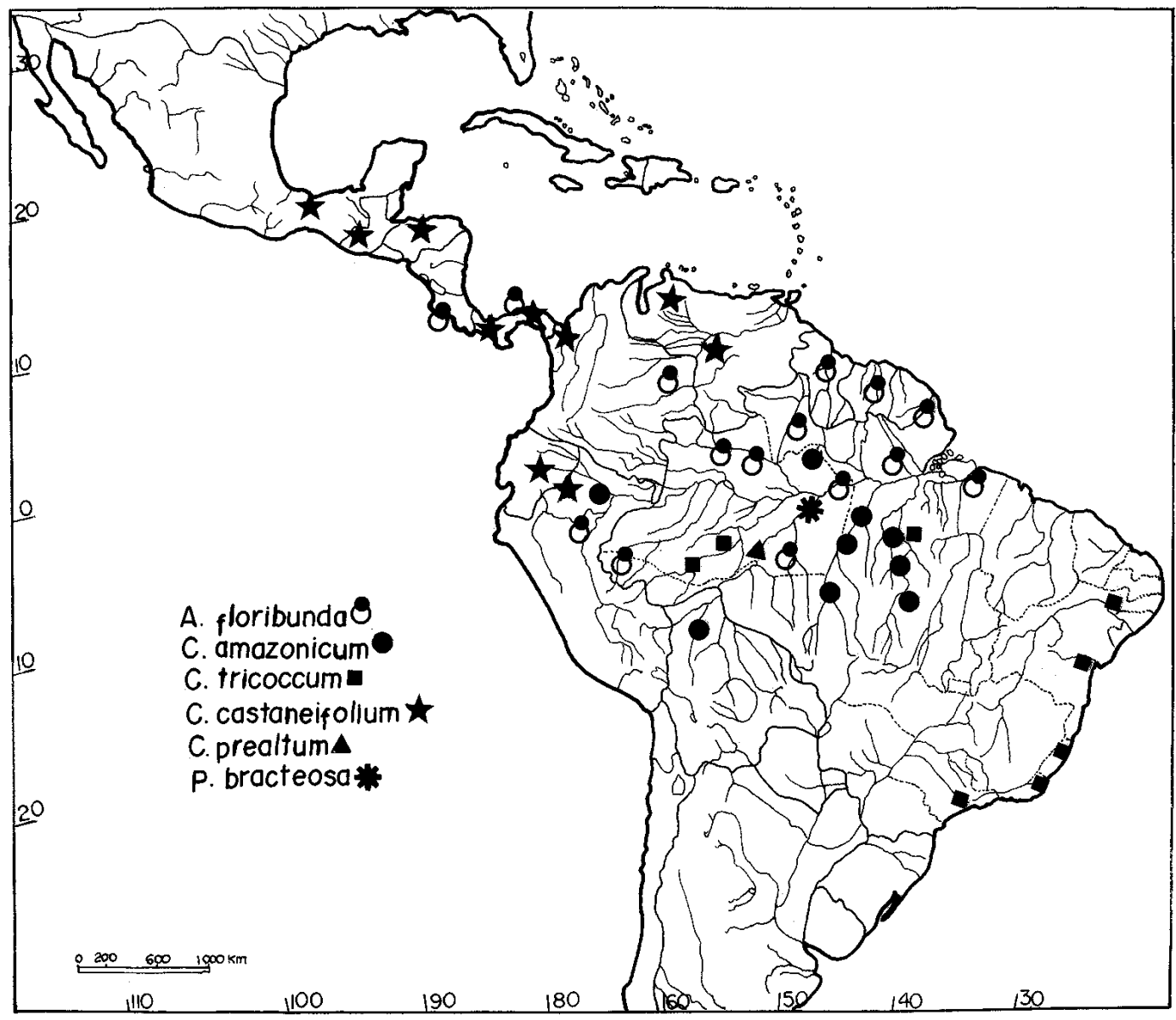

Figura 17. Distribuição geográfica de Alchorneopsis floribunda, Cleidion amazonicum, C. tricoccum, C. castaneifolium, C. prealtum e Polyandra bracteosa na região neotropical.

Leal (1951) forneceu uma descrição detalhada deste gênero e da espécie, bem como uma boa ilustração de $P$. bracteosa. Apesar disso, a identidade e a posição sistemática de Polyandra ainda são objetos de controvérsia.

Webster \& Huft (1988) sugeriram que $P$. bracteosa talvez fosse um sinônimo de Cleidion prealtum Croizat (Croizat 1943), embora Webster (1994) tenha mantido Polyandra como membro da tribo Alchorneae, subtribo Conceveibinae, juntamente com Conceveiba.

Webster (1994) diferenciou Polyandra de Conceveiba por este primeiro gênero apresentar inflorescência estaminada axilar e anteras obtusas, sem qualquer apêndice na terminação das tecas. A análise do holótipo de $P$. bracteosa mostrou que as anteras apresentam tecas bastante separadas entre si, sugerindo a existência de duas anteras em um mesmo filete. Esta característica afastaria Polyandra da subtribo Conceveibinae, aproximando-o superficialmente do gênero Cleidion Blume, que apresenta as anteras 4-loculares e está incluído na tribo Acalypheae, subtribo Cleidiinae (Webster 1994). A análise do isótipo de Cleidion prealtum revelou que a amostra possui apenas flores pistiladas, o que dificultou compará-la com Polyandra bracteosa, cujo exemplar apresenta apenas flores estaminadas, embora as folhas cartáceas, com as margens crenadas aproximem bastante as duas 
espécies. Pelas diagnoses das duas espécies, podem ser apontados outros aspectos que aproximam $C$. prealtum de $P$. bracteosa. o número de estames (50); o número de sépalas da flor estaminada (34), e o local da coleta dos tipos desses táxons no rio Madeira, Estado do Amazonas (Fig. 17), com a diferença que a primeira espécie é da cidade de Humaitá e a segunda, de Borba.

Tanto $P$. bracteosa como $C$. prealtum apresentam tricomas estrelados, o que as afasta das espécies neotropicais de Cleidion, cujos tricomas são simples. Além disso, os estiletes de $C$. prealtum (Fig. 13) são concrescidos com o ovário, apresentando um padrão similar aos estiletes de Conceveiba. Isto representa uma outra característica incomum às demais espécies neotropicais de Cleidion, cujos estiletes não são concrescidos com o ovário (Fig. 6, 8) e são facilmente destacados dessa estrutura. Provavelmente, Polyandra é um gênero válido e $C$. prealtum é a planta com flores pistiladas de $P$. bracteosa.

Diante do exposto, concordou-se parcialmente com Webster (1994) na conservação de Polyandra como gênero diferente de Cleidion, porém sugerindo sua retirada da subtribo Conceveibinae para a subtribo Cleidiinae Webster, na tribo Acalypheae Dumortier.

\section{Agradecimentos}

Ao CNPq, pela Bolsa de Pesquisa (Processo n. 301.252-86-6 ) concedida ao autor para estudar as Euphorbiaceae; à Dra. Daniela C. Zappi, do Royal Botanic Gardens, Kew, pelas referências bibliográficas enviadas; à Dra. Inês Cordeiro, do Instituto de Botânica de São Paulo, pelas informações sobre Cleidion do Sudeste do Brasil; à Profa. Regina C. Vianna Martins da Silva, curadora do herbário IAN, pelas facilidades concedidas durante a estada do autor naquela instituição; ao desenhista Antonio Elielson, bolsista do PCI/CNPq, pela elaboração dos desenhos; à Ione Bemerguy, bolsista do $\mathrm{PCI} / \mathrm{CNPq}$, pela digitação do texto, e aos revisores pelas sugestões apresentadas.

\section{Referências bibliográficas}

Andrade-Lima, D. 1966. Contribuição ao estudo do paralelismo da flora amazônico-nordestina. Boletim Técnico do Instituto de Pesquisa Agronômico de Pernambuco, n. ser., 19: 1-30.

Baillon, H. 1863. Euphorbiacées Américaines. Adansonia 4: 370.

Caballero, I. G. V. 1993. Euphorbiaceae. In: Killeen, T. J. et al. (Eds.). Guia des Arboles de Bolivia. Ed. Herb. Nac. Bolivia/Missouri Bot. Gard. Bolivia, La Paz, pag. 288-315, 958p.

Croizat, L. 1943. Novelties on American Euphorbiaceae. Journal of the Arnold Arboretum Harvard University 24: 167.

Gentry, A. H. 1982. Neotropical floristic diversity: phytogeographical connections between Central and South America, Pleiostecene climaticfluctuations, or an accident of the Andean orogeny ? Ann. Missouri Gard. 69 (3): 557-593.

Gillespie, L. J. 1993. Euphorbiaceae of the Guianas: annotated species checklist and key to the genera. Brittonia 45(1): 59-94.

Jablonski, E. 1967. Euphorbiaceae. In: B. Maguire (Ed.), Botany of Guayana Highland - Part VII. Memoirs of the New York Botanical Garden 17: 80-190.

Lanjouw, J. 1931. The Euphorbiaceae of Surinam. J. H. de Bussy, Amsterdam.

Leal, C. 1951. Contribuição ao estudo da família Euphorbiaceae. Arquivos do Jardim Botanico do Rio de Janeiro 11: 63-79.

Méroz, J. 1990. Euphorbiaceae. In: R. Spichiger et al. (Eds.), Contribución a la flora de la Amazonia Peruana. Boissiera 44: 42-78.

Mueller, J. 1865. Euphorbiaceae. Linnaea 34: 184.

Nowicke, J. W.; Takahashi, M. \& Webster, G. L. 1999. Pollen morphology, exine estructure and systematics of Acalyphoideae (Euphorbiaceae). Part 2. Agrostistachydeae, Chrozophoreae, Caryodendreae, Bernardieae and Pycnocomeae. Review of Paleobotany and Palynolnology 105: 1-62.

Pax, F. \& Hoffmann, K. 1919. Euphorbiaceae. In: A. Engler (editor). Das Pflanzenreich IV. 147. XIV: 23.

Smith, A. C. 1973. Angiosperms evolution and the relationship of the floras of Africa and America. In: B. J. Meggers et al. (Eds.). Tropical forest ecossystems in Africa and South America: a comparative review. Smithsonian Inst., Washington.

Thorne, R. F. 1973. Floristic relationship between Tropical África and Tropical América. In: B. J. Meggers et al. (Eds.). Tropical Forest Ecosystems in Africa and South America: a comparative review. 
Smithsonian Inst., Washington.

Urban, I. 1899. Species novae, praesertim portoricenses. Symbollae Antillanae Vol. 337.

Webster, G. L. 1994. Synopsis of the genera and suprageneric taxa of Euphorbiaceae. Annals of the
Missouri Botanical Garden 81: 33-144.

Webster, G. L. \& Huft, M. J. 1988. Revised Synopsis of Panamanian Euphorbiaceae. Annals of the Missouri Botanical Garden 75: 1087-1144. 